\title{
Study on The Optimal Order Quantity of single-period products Returned for Continuous Demand
}

\author{
Fengju Cheng ${ }^{1, a}$, Jingzhao Zhang ${ }^{2, b^{\star}}$ and Lili Xue ${ }^{3, c}$ \\ ${ }^{1}$ Qingdao HuangHai University, 266427,China \\ ${ }^{2}$ Geological Surveying \& Mapping Institute of Shandong Province, 250001,China \\ ${ }^{3}$ Qingdao HuangHai University, 266427,China \\ a961123624@qq.com, b564158441@qq.com, c2556367929@qq.com
}

\begin{abstract}
Keywords: Inventory control problem, Classical newsboy problem, The Optimal Order Quantity of single-period products
\end{abstract}

\begin{abstract}
In this paper, we consider the inventory control problem of single-period product items with a fixed life cycle and short marketing period. Our study expands the classical newsboy problem to consider defective items and returning policy. The single-period model is established, and the optimal order quantity is derived for cases when the expect profit model in the supplier and the retailer operate independently as well as collaboratively. Then numerical examples and sensitivity analysis are carried out to illustrate the application of the model. Research results show that the profit of them under collaboration is bigger than independence respectively.
\end{abstract}

\section{Introduction}

In recent years, with the development of economic globalization, pressure of global competition is seriously increasing, which not only speeds up the pace of product development, but also makes life cycles of a lot of products get shorter, and consumers' picking commodity become more flexible. For some products which are unable to accurately forecast its demand, especially the modish and perishable goods, competition is more intense, and changes in demand is very large by the limitations of timeliness. In real life, a newsboy problem discussed in goods is quite common, such as: milk, bread and other foods; newspapers, weekly magazines, Christmas cards and other commodities, If they are not sold within the validity period, they will be sold in a lower price or be regarded as something waste, because the valid time of these commodities is one period, and ending inventory can not be transferred to the next period of demand. Therefore, newsboy problem on inventory management and decision analysis, should be paid to considerable attention.

\section{Traditional significance and characteristics of newsboy problem}

Single-cycle products is a single-period random demand-architecture, discussion on a single commodity in a single cycle of order and a single point of sale inventory decision-making, expects profit-maximization case solving the optimal order quantity, to cope with future products within a single cycle of random demand. Traditional single-cycle issues (newsboy), with the following four characteristics:

(1)Only a single point of sale and demand faced by this point of sale is a random variable.

(2)Point of sale order the product once only before the beginning of the sales period, during the sales period which can no longer be ordered.

(3) The timeliness of the product itself, after the deadline, the remaining products are not to be used for the next cycle. Therefore, after the deadline, if there is surplus, should be immediately disposed of, for example, at a lower price (the residual value) to sell, or waste disposal.

(4)The purpose is to determine the optimal order quantity of points of sale, to maximize sale profits or minimize costs.

We meet the four attributes of the above stock decision problems, commonly known as the "traditional newsboy problem". Problem belonging to the newsvendor model in real life are also very much, very wide range of applications, for example: the newspaper or weekly sales, milk sales, sales of Christmas cards 


\section{The best order quantity of continuous demand for the returning single-period products}

As for stock problem of single cycle, traditional newsboy problem will be expanded. When procurement bulk contains bad product, and retailers before the selling product don't check any quality's test, and then some bad products are all returned. After ending cycle, regardless of retailers also suppliers they also process the returned goods and final remaining goods, at a lower price $S$ to sale, and totally can finish sale. For the profit of the entire supply chain, create two-level supply chain of a single manufacturer and a single retailer, use mathematical models under uncertain demand environment to explore single-period inventory decision model for cooperation and lack of cooperation between retailers and suppliers for optimal order quantity decision in both cases.

\section{Description of the problem}

Retailers face random demand in market which can not be determined of, if order too more, in a certain period cannot all be sold, will lose product's value and cannot sale again, or only left residual value, cause cost of a large burden; instead, if order too less, may lost opportunities of busies because of stock insufficient. Newsboy who in corner or kiosk sales newspaper most often face this case; In addition, as stock of epidemic product, department stores, bookstore, and supermarket or bread shop and so on all belong to the scope of discussion on the single-period inventory model.

In order to achieve the objective of the most profitable in two-level supply chain, will discuss the best order quantity in both cases--cooperation and lack of cooperation between retailers and suppliers.

A. Model without the cooperation between retailers and suppliers:

Separately establishing retailers and suppliers total expected profit function, and from the retailer's perspective, in the case production costs of suppliers, wholesale prices, the sale price which retailer based on, and the surplus product of residual value all determining, under the principle which retailers pursuit the profit maximization, get the optimal order quantity decision.

B. Cooperation between retailers and suppliers of model

In the case of cooperation between retailers and suppliers, taking the retailers and manufacturers as a whole, in the case of fixed sales price and the residual value, set up overall total expected profit function based on the buyers and sellers, determine the optimal order quantity, that is, in the case of maximum profit of two-stage supply chain for retailers and suppliers, the optimal order quantity of retailers.

Basic assumptions of model

The mathematical model of main assumptions which is explored are as follows:

(1) Discuss a single commodity inventory in a cycle time

(2)The product itself have timeliness, the end of the stock can not be transferred to the next time;

(3)Consumer demand for commodities as a continuous random variable, its mean ${ }^{\mu_{X}}$ and variance ${ }^{\sigma_{X}}$;

(4) The defective products which are sold by retailers are all returned by consumers, and the return rate is a constant $r$;

(5) whether retailers or suppliers, they all reduce price to sell the goods which are returned and the end of the season remaining goods, as price $S$;

(6) Retailers order products from a supplier as price $w$ and as a fixed retail price $p$ to sell, and the supplier's production cost is $c$. Without loss of generality, we assume $p>w>c>s$.

Model symbol description

Explanation of symbols used in this article are as follows: 
Table 1 model symbol description

\begin{tabular}{|l|l|}
\hline$Q$ & Retailer orders \\
\hline$F(X)$ & Distribution function of demand \\
\hline$X$ & The retailer's demand in a Cycle time \\
\hline$f(X)$ & The probability density function of demand X $(p . d . f)$ \\
\hline$\mu_{X}$ & The average demand of consumers \\
\hline$\sigma_{X}$ & Standard deviation of consumer's demand \\
\hline$w$ & Wholesale price which retailers pay to the supplier \\
\hline$p$ & In the final market price of the commodity, namely retail price \\
\hline$c$ & Production cost per unit product \\
\hline$\Pi$ & Profit function \\
\hline$T$ & The subscript text On behalf of taking the retailers and suppliers as a whole \\
\hline$R$ & The subscript text On behalf of retailers \\
\hline$S$ & The subscript text on behalf of suppliers \\
\hline$r$ & Products defective rate of retailers ordering quantity \\
\hline$s$ & Defective products and residual value of the end of season remaining products \\
\hline
\end{tabular}

\section{Mathematical model}

\section{Model A - retailers and suppliers are not cooperative case model}

Separately establishing retailers and suppliers total expected profit function, and from the retailer's perspective, in the case production costs of suppliers, wholesale prices, the sale price which retailer based on, and residual value of the surplus product all determining, under the principle which retailers pursuit the profit maximization, get the optimal order quantity decision.

Therefore, we start from the retailer's perspective, to model retailer's profits, and $X$ and $X>Q_{\text {two cases }}$ will be considered in the model to reflect too much inventory (Over-stocking) and lack of inventory (Under-stocking) expected the maximum total profit in both cases (or the minimum total cost), model description is as follows:

(1)When $X \leq Q$ :

Indicate that demand is less than or equal to the quantity of supply in a cycle time. After $X$ demand is sold, there will be $r X$ units of defective products which are returned. And in the case of demand less than the amount ordered quantity, there will be overstock, retailers are sold goods whether it is a bad product or surplus products as price $S$. So in the case of $X \leq Q$, the derivation process of retailer's profit is as follows:

Sales in a cycle time $=(1-r) X$

The commodities unit profit in the cycle time $=p-w$

Defective products and the total number of surplus stock in the end of cycle time $=Q-X+r X$

Unit cost of losses caused by unsalable goods in the end of the cycle $=s-w$

By (2.1) to (2.4), you can find out in the case $X \leq Q$, retailers ' profits are:

$$
\prod_{R}=(p-w) \cdot(1-r) x+(s-w) \cdot(Q-X+r X)=p(1-r) X+s(Q-X+r X)-w Q
$$

(2)When $X>Q$ :

Indicate that demand is more than the quantity of supply in a cycle time. After $X$ demand is sold, there will be $r X$ units of defective products which are returned. And in the case of demand more than the amount ordered 
quantity, all goods will be sold, retailers are sold goods whether it is a bad product or surplus products as price $^{S}$. So in the case of $X>Q$, the derivation process of retailer's profit is as follows:

Sales in a cycle time $=(1-r) Q$

The commodities unit profit in the cycle time $=p-w$

Defective products and the total number of surplus stock in the end of cycle time $=r Q$

Unit cost of losses caused by unsalable goods in the end of the cycle $=s-w$

By (2.5) - (2.8), you can find out in the case $X>Q$, retailers ' profits are:

$\prod_{R}=(p-w) \cdot(1-r) Q+(s-w) \cdot r Q=p(1-r) Q+s r Q-w Q$

Therefore, by (1), (2) we can know that retailers ' profits are as follows:

$$
\prod_{R}= \begin{cases}=p(1-r) X+s(Q-X+r X)-w Q & \text { 当 } \mathrm{X} \leq \mathrm{Q} \text { 时 } \\ =p(1-r) Q+s r Q-w Q & \text { 当 } \mathrm{X}>\mathrm{Q} \text { 时 }\end{cases}
$$

As $\mathrm{X}$ is a continuous random variable, so that the total expected profit function can be expressed as follows:

$$
\begin{aligned}
& \prod_{R}^{*}(Q)=\int_{0}^{Q}[p(1-r) X+s(Q-X+r X)-w Q] f(X) d X+\int_{Q}^{\infty}[p(1-r) Q+s r Q-w Q] f(X) d X \\
& +s(Q-X+r X)-w Q] f(X) d X+\int_{Q}^{\infty}[p(1-r) Q+s r Q] f(X) d X-w Q \\
& \prod_{R}^{*}(Q)=\int_{0}^{Q}[p(1-r) X+s(Q-X+r X)-w Q] f(X) d X+\int_{Q}^{\infty}[p(1-r) Q+s r Q-w Q] f(X) d X \\
& {[p(1-r) X+s(Q-X+r X)-w Q] f(X) d X} \\
& \prod_{R}^{*}(Q)=\int_{0}^{Q}[p(1-r) X+s(Q-X+r X)] f(X) d X \\
& =\int_{0}^{Q}[p(1-r) X+s(Q-X+r X)] f(X) d X+\int_{Q}^{\infty}[p(1-r) Q+\operatorname{sr} Q] f(X) d X-w Q
\end{aligned}
$$

From the retailer's perspective, in the case production costs of suppliers, wholesale prices, the sale price which retailer based on all determining, establish retailer's expectation profit function and get the optimal order quantity decision. However in order to determine that the great value of this model exists, that is the optimal order quantity, first judge the concave-convex of the retailer's expected total profit function $\mathrm{x}$ through two derivative, prove formula (2.9) has great value:

Because

$$
\begin{aligned}
\prod_{R}^{*}(Q) & =\int_{0}^{Q}[p(1-r) X+s(Q-X+r X)] f(X) d X+\int_{Q}^{\infty}[p(1-r) Q+s r Q] f(X) d X-w Q \\
= & \int_{0}^{Q}[p(1-r) X+s(Q-X+r X)] f(X) d X+[p(1-r)+s r] \int_{Q}^{\infty} Q f(X) d X-w Q \\
= & \int_{0}^{Q}[p(1-r) X+s(Q-X+r X)] f(X) d X+[p(1-r)+s r][Q(1-F(Q)]-w Q
\end{aligned}
$$

So: 


$$
\begin{aligned}
& \frac{d \prod_{R}^{*}(Q)}{d Q}=[p(1-r) Q+s(Q-Q+r Q)] f(Q)+[p(1-r)+s r][1-F(Q)-Q f(Q)]-w \\
& =[p(1-r)+s r][1-F(Q)]-w \\
& \frac{d^{2} \prod_{R}^{*}(Q)}{d Q^{2}}=[p(1-r)+s r] \cdot[-f(Q)] \\
& \text { Because }[p(1-r)+s r]>0, f(Q)>0 \text {, so that }[p(1-r)+s r] \cdot[-f(Q)]<0 \text {, that } \\
& \text { is: } \frac{d^{2} \prod_{R}^{*}(Q)}{d Q^{2}}<0
\end{aligned}
$$

From the above, $\prod_{R}^{*}(Q)$ is concave function of $Q$, so retailer's order quantity has profit maximum, set the optimal order quantity $Q_{R}^{*}$. Therefore, we can solve the first derivative of formula (2.9) and set it equal zero to obtain the optimal order quantity of the retailer $Q_{R}^{*}$. That is:

$$
\begin{aligned}
\frac{d \prod_{R}^{*}(Q)}{d Q} & =[p(1-r) Q+s(Q-Q+r Q)] f(Q)+[p(1-r)+s r][1-F(Q)-Q f(Q)]-w \\
= & {[p(1-r)+s r][1-F(Q)]-w=0 }
\end{aligned}
$$

So, you can get:

$$
F\left(Q_{R}^{*}\right)=\frac{p(1-r)+s r-w}{p(1-r)+s r}=\frac{p(1-r)+s r-w}{p(1-r)+s r}
$$

Therefore, through above formula we can get the optimal order quantity $Q_{R}^{*}$, it meets the following:

$$
Q_{R}^{*}=F^{-1}\left(\frac{p(1-r)+s r-w}{p(1-r)+s r}\right)
$$

Therefore, we can know that, when we stand on the retailer's standpoint, to pursue their own profit maximization, retailers place an order for $Q_{R}^{*}$ products to suppliers with wholesale prices $w$ and sale to consumers at the price $p$, retailers will produce maximum profit.

\section{Model b-cooperation between retailers and suppliers of model}

In the case of cooperation between retailers and suppliers, taking the retailers and manufacturers as a whole, in the case of fixed sales price and the production cost, set up overall total expected profit function based on the buyers and sellers, determine the optimal order quantity, that is, in the case of maximum profit of two-stage supply chain for retailers and suppliers, the optimal order quantity of retailers. By the previous assumptions we can see, when the retailer's order quantity is $Q$, the supplier's profit function is:

$$
\prod_{s}^{\prime}(Q)=(w-c) Q
$$


Put retailers and suppliers as a whole, the total expected profit function is shown as the following formula, that is, the sum of $\prod_{R}^{*}(Q)$ and $\prod_{S}^{*}(Q)$, the function can be expressed as the following model:

$$
\begin{aligned}
& \prod_{T}^{*}(Q)=\int_{0}^{Q}[p(1-r) X+s(Q-X+r X)] f(X) d X+\int_{Q}^{\infty}[p(1-r) Q+s r Q] f(X) d X \\
& \prod_{T}^{*}(Q)=\int_{0}^{Q}[p(1-r) X+s(Q-X+r X)] f(X) d X+\int_{Q}^{\infty}[p(1-r) Q+\operatorname{sr} Q] f(X) d X \\
& -w Q+(w-c) Q-w Q+(w-c) Q
\end{aligned}
$$

In order to determine in the case of cooperation between retailers and suppliers, the total expected profit function exists maximum value, that is, the optimal order quantity, first judge the concave-convex of the retailer's expected total profit function $\mathrm{x}$ through two derivative, the results are as follows:

$$
\begin{aligned}
\prod_{T}^{*}(Q)= & \int_{0}^{Q}[p(1-r) X+s(Q-X+r X)] f(X) d X+\int_{Q}^{\infty}[p(1-r) Q+s r Q] f(X) d X \\
& -w Q+(w-c) Q \\
= & \int_{0}^{Q}[p(1-r) X+s(Q-X+r X)] f(X) d X+[p(1-r)+s r] \int_{Q}^{\infty} Q f(X) d X \\
& -w Q+(w-c) Q \\
= & \int_{0}^{Q}[p(1-r) X+s(Q-X+r X)] f(X) d X+[p(1-r)+s r][Q(1-F(Q)]-c Q \\
\frac{d \prod_{T}^{*}(Q)}{d Q}= & {[p(1-r) Q+s(Q-Q+r Q)] f(Q)+[p(1-r)+s r][1-F(Q)-Q f(Q)]-w } \\
= & {[p(1-r)+s r][1-F(Q)]-c \frac{d^{2} \prod_{T}^{*}(Q)}{d Q^{2}}=[p(1-r)+s r] \cdot[-f(Q)] }
\end{aligned}
$$

Also, since $[p(1-r)+s r]>0, f(Q)>0$, so be aware $[p(1-r)+s r] \cdot[-f(Q)]<0$, that is: $\frac{d^{2} \prod_{T}^{*}(Q)}{d Q^{2}}<0$

From the above, $\prod_{R}^{*}(Q)$ is concave function of $Q$, so retailer's order quantity has profit maximum in the case of cooperation between retailers and suppliers, set the optimal order quantity $Q_{T}^{*}$. Therefore, we can solve

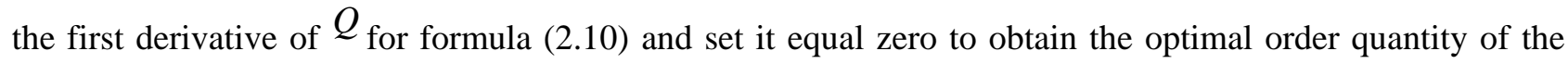
retailer

That

$$
\frac{d \prod_{T}^{*} Q}{d Q}=[p(1-r) Q+s(Q-Q+r Q)] f(Q)+[p(1-r)+s r][1-F(Q)-Q f(Q)]-c
$$

is:

$$
=[p(1-r)+s r][1-F(Q)]-c=0
$$

So, you can

$$
\text { get: } F\left(Q_{T}^{*}\right)=\frac{p(1-r)+s r-c}{p(1-r)+s r}=\frac{p(1-r)+s r-c}{p(1-r)+s r} \text {. }
$$

Thus, by the above formula, we can get the retailer's optimal order quantity $Q_{R}^{*}$ in the case of cooperation between retailers and suppliers, it meets the following formula $Q_{T}^{*}=F^{-1}\left(\frac{p(1-r)+s r-w}{p(1-r)+s r}\right)$. 
Therefore, we can see that, when we put retailers and suppliers as a whole, the pursuit of the maximum total profit of retailers and suppliers, that suppliers (retailers) produce (order) the number of ${ }^{*}$ will make the two level supply chain get profit maximum.

Analysis and comparison of the optimal order quantity and supply chain overall income of the two models

From a retailer's perspective, the optimal order quantity is $Q_{R}^{*}$, meets $F\left(Q_{R}^{*}\right)=\frac{p(1-r)+s r-w}{p(1-r)+s r}$; If we put retailers and suppliers as a whole, the optimal order quantity is $Q_{T}^{*}$, meets $F\left(Q_{T}^{*}\right)=\frac{p(1-r)+s r-c}{p(1-r)+s r}$, by assumption, if $w>c$, then

$$
\frac{p(1-r)+s r-w}{p(1-r)+s r}<\frac{p(1-r)+s r-c}{p(1-r)+s r}
$$

That is $F\left(Q_{R}^{*}\right)<F\left(Q_{T}^{*}\right)$, therefore $Q_{R}^{*}<Q_{T}^{*}$.

(1) In the case of independent retailers the supply chain profit analysis

In the case of the uncooperation $Q_{R}^{*}$ is retailer's optimal order quantity, the retailer's expected profit:

$\prod_{R}^{*}\left(Q_{R}^{*}\right)=\int_{0}^{Q_{R}^{*}}\left[p(1-r) X+s\left(Q_{R}^{*}-X+r X\right)\right] f(X) d X+\int_{Q_{R}^{*}}^{\infty}\left[p(1-r) Q_{R}^{*}+s r Q_{R}^{*}\right] f(X) d X-w Q_{R}^{*}$

Supplier's expected profit:

$\prod_{S}^{*}\left(Q_{R}^{*}\right)=(w-c) Q_{R}^{*}$

The total expected profit in supply chain:

$\prod_{T}^{1}\left(Q_{R}^{*}\right)=\prod_{R}^{*}\left(Q_{R}^{*}\right)+\prod_{T}^{*}\left(Q_{R}^{*}\right)$

(2) In the case of collaboration between retailers and suppliers supply chain profit analysis

In the case of the cooperation $Q_{T}^{*}$ is retailer's optimal order quantity, put retailer and supplier as a whole, the total expected profit:

$$
\begin{aligned}
\prod_{T}^{2}\left(Q_{T}^{*}\right)= & \int_{0}^{Q_{T}^{*}}\left[p(1-r) X+s\left(Q_{T}^{*}-X+r X\right)\right] f(X) d X+\int_{Q_{T}^{*}}^{\infty}\left[p(1-r) Q_{T}^{*}+s r Q_{T}^{*}\right] f(X) d X \\
& -w Q_{T}^{*}+(w-c) Q_{T}^{*}
\end{aligned}
$$

By the above we know $Q_{R}^{*}<Q_{T}^{*}, \prod_{T}^{1}\left(Q_{R}^{*}\right)<\prod_{T}^{2}\left(Q_{T}^{*}\right)$ can be deduced, the total profit of the supply chain in the case of cooperation is greater than the total supply chain profits in the case of uncooperative.

\section{Case study}

Through case analyze the model A and the model B, discuss the optimal order quantity in the case of independent retailers and cooperation between retailers and suppliers, illustrate the application of the model established in this paper.

Model A- the optimal order quantity and profit analysis in the case of independent retailers

A large bookstore chain sells a monthly, if the monthly demand approximates a normal distribution, the average demand per month is 500 , the standard deviation is 100 , and each monthly sells at the price 12 yuan, sold to 18 yuan, the bookstore don't do any quality inspection work before selling monthly, customers will return the defective products, if the defect rate of the monthly is $r=0.1$, at the end of the month bookstore sells at a discount defective products which are returned by customers and residual monthly at the price 8 yuan, and can always be sold out. How the bookstore a month should order amount monthly in order to obtain the maximum profit?

Based on the above, sort out the data as follows: 
Average demand of bookstore $\mu_{X}=500 /$ month;

Standard deviation of bookstore demand $\sigma_{X}=100 /$ month;

Monthly sale price ${ }^{p}=18$ yuan;

Monthly wholesale price ${ }^{W}=12$ yuan;

Monthly residual value $S=8$ yuan;

The optimal order quantity meets the next formula:

$$
F\left(Q_{R}^{*}\right)=1-\frac{12}{18 \cdot(1-0.1)+8 \cdot 0.1}=0.2941
$$

So $Q_{R}^{*}=F^{-1}(0.2941)$

By the above cases, we know the monthly demand approximate normal distribution, so standardizing the result of above formula, we can be drawn the optimal order quantity of bookstore, that is:

$X \sim N\left(500,100^{2}\right) 、 Z_{R}^{*}=-0.54$

$$
\text { Then } Q_{R}^{*}=500+100 \cdot(-0.54)=446, \prod_{R}^{*}(446)=2062
$$

Therefore, from the above formula, when the bookstore orders quantity $Q_{R}^{*}=446$, the bookstore can get maximum profit, the profit is 2062 yuan.

Model B- the optimal order quantity and profit analysis in the case of cooperation between supplier and retailers

A large bookstore chain sells a monthly, if the monthly demand approximates a normal distribution, the average demand per month is 500 , the standard deviation is 100 , and monthly production cost is 10 yuan, wholesale price is 12 yuan sold to bookstores, bookstore sell at the price 18 yuan, the bookstore don't do any quality inspection work before selling monthly, customers will return the defective products, if the defect rate of the monthly is $r=0.1$, at the end of the month bookstore sells at a discount defective products which are returned by customers and residual monthly at the price 8 yuan, and can always be sold out. How the bookstore a month should order amount monthly in order to obtain the maximum profit?

Based on the above, sort out the data as follows:

Based on the above, sort out the data as follows:

Average demand of bookstore $\mu_{X}=500 /$ month;

Standard deviation of bookstore demand $\sigma_{X}=100 /$ month;

Monthly sale price ${ }^{p}=18$ yuan;

Monthly wholesale price $w=12$ yuan;

Monthly production cost $c=10$ yuan;

Monthly residual value $S=8$ yuan;

The optimal order quantity meets the next formula:

$$
F\left(Q_{T}^{*}\right)=1-\frac{10}{18 \cdot(1-0.1)+8 \cdot 0.1}=0.4118
$$

So $Q_{T}^{*}=F^{-1}(0.4118)$

By the above cases, we know the monthly demand approximate normal distribution, so standardizing the result of above formula, we can be drawn the optimal order quantity of bookstore, that is:

$$
\begin{aligned}
& X \sim N\left(500,100^{2}\right) 、 Z_{T}^{*}=-0.22 \\
& \text { Then } Q_{T}^{*}=500+100 \cdot(-0.22)=478 \\
& \prod_{T}^{*}(478)=3077
\end{aligned}
$$

Therefore, from the above formula, when the bookstore orders quantity $Q_{T}^{*}=478$, the bookstore can get maximum profit, the profit is 3077 yuan. We find that the optimal order quantity in case of taking publishers 
and bookstores as a whole is more than it in case of simply considering the bookstore, overall profit is bigger also.

\section{Sensitivity analysis}

First at the different parameters, analyze the optimal order quantity and the expected profit in the case of independent retailers and cooperation between retailers and suppliers and the supply chain revenue in both cases. Set market demand which retailers face obey the normal distribution of the parameters $\mu_{X}=500$ 、 $\sigma_{X}=100$, retail price $p=18$ yuan, wholesale price $w=12$ yuan, production cost $c=10$ yuan. Table 2.2 shows the optimal order quantity and the expected profit in the case of independent retailers and cooperation between retailers and suppliers and the supply chain revenue in both cases when the defect

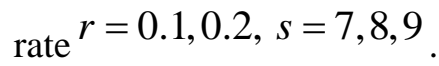

Table 2 order under different parameters as well as supply chain expectations profits

\begin{tabular}{|c|l|l|l|l|l|l|l|}
\hline$r$ & $S$ & $Q_{R}^{*}$ & $Q_{T}^{*}$ & $\prod_{R}^{*}\left(Q_{R}^{*}\right)$ & $\prod_{S}^{*}\left(Q_{R}^{*}\right)$ & $c$ & $\prod_{T}^{2}\left(Q_{T}^{*}\right)$ \\
\hline 0.1 & 7 & 445 & 477 & 2000 & 850 & 2850 & 3000 \\
\hline 0.1 & 8 & 446 & 478 & 2062 & 892 & 2954 & 3077 \\
\hline 0.1 & 9 & 447 & 476 & 2127 & 894 & 3021 & 3145 \\
\hline 0.2 & 7 & 430 & 466 & 1508 & 860 & 2368 & 2481 \\
\hline 0.2 & 8 & 433 & 468 & 1140 & 866 & 2006 & 2601 \\
\hline 0.2 & 9 & 435 & 470 & 1715 & 870 & 2585 & 2722 \\
\hline
\end{tabular}

Table 2 you can draw the following conclusions:

We find that the optimal order quantity in case of cooperation between retailers and suppliers is more than it in case of uncooperation, and the total expected profit of supply chain is bigger also.

With the $r$ increase, when $s$ remain unchanged, the retailer's optimal order quantity and expected profits significantly reduce; supplier's expected profit and the entire expected profit of the supply chain is also reduced.

With $S$ increase, when $r$ remain unchanged, the retailer's optimal order quantity and expected profits significantly increase; supplier's expected profit and the entire expected profit of the supply chain also increase.

Analyze the whole profit of supply chain, when the supplier's production cost is respectively 9,10 , $11, r=0.1, s=8$,and other parameters as in table 2.2. Table 2.3 gives the total profit of the supply chain in the case of cooperation and noncooperation.

Table 3 The total profit of the supply chain under different cost

\begin{tabular}{|c|c|c|c|}
\hline$c$ & 9 & 10 & 11 \\
\hline$\prod_{T}^{1}\left(Q_{R}^{*}\right)$ & 3400 & 2954 & 2508 \\
\hline$\prod_{T}^{2}\left(Q_{T}^{*}\right)$ & 3615 & 3077 & 2559 \\
\hline
\end{tabular}

Table 3 you can draw the following conclusions:

With $c$ increase, the other parameters remain unchanged, regardless of the retailer and supplier cooperation or non-cooperation, the total supply chain profit tends to decrease.

No matter how much production costs, in the case of cooperation between retailers and suppliers the total profit of supply chain are greater than in the case of uncooperation. 


\section{Conclusions}

Focus of this paper is the traditional newsboy problem to be expanded to make it more in line with the actual situation. In this paper, discuss the problem of single-cycle optimal order quantity when the demand approximately obey a continuous distribution and product can be returned. From model, numerical examples and sensitivity analysis built in this paper, we can conclude the following conclusions:

(1) When the return rate $r$ increases, the retailer's expected profits, and optimal order quantity and the total profit of the supply chain will significantly reduced

(2) When dealing with the price $S$, production $\operatorname{costs}^{c}$ rise, the retailer's optimal order quantity, the total expected profit and the whole profit of supply chain will increase, too. And the optimal order quantity in the case of cooperation between retailers and suppliers is always greater than the one in the case of uncooperation.

\section{References}

[1] Kogan K. Scheduling parallel machines by the dynamic newsboy problem, Computers \& Operations Research[J], 2004,31:429-443.

[2] Hahn K H, Hwang H, Shinn S W. Returns policy for distribution channel coordination of perishable items, European Journal of Operational Research[J], 2004,152:770-780.

[3] Stock J, Speh T, Shear H. Many Happy (product) Returns, Harvard Business Review[J], 2002,80(7):16-17.

[4] Elahi E, Lamba N, Ramaswamy C. How can we improve the performance of supply chain contracts? An experimental study[J]. International Journal Production Economics, 2013, 142(1):146-157.

[5] Kremer M, Minner S, Wiassenhove L N. On the preference to avoid ex-post inventory errors[J]. Production and Operations Management, 2014,23(5):773-787.

[6] Davis A M. An Experimental investigation of pull contracts in supply chains[J]. Production and Operations Management, 2015, 24(2):325-340. 